\title{
ALTERAÇÕES ULTRA-SONOGRÁFICAS NA GRAVIDEZ Rh NEGATIVO SENSIBILIZADA AVALIADA PELA ESPECTROFOTOMETRIA DO LÍOUIDO AMNIÓTICO E PELA DOPPLERVELOCIMETRIA DA ARTÉRIA CEREBRAL MÉDIA*
}

\author{
Luciano Marcondes Machado Nardozza', Luiz Camano², Antonio Fernandes Moron², \\ David Baptista da Silva Pares ${ }^{3}$, Paulo Alexandre Chinen ${ }^{4}$, Guilherme Antonio Rago Lobo ${ }^{4}$
}

Resumo OBJETIVO: Avaliar e confrontar a presença de alterações ultra-sonográficas nas gestações Rh negativo sensibilizadas, quando a anemia fetal foi determinada ou pela espectrofotometria do líquido amniótico, ou pela dopplervelocimetria da artéria cerebral média. MATERIAIS E MÉTODOS: Observacional descritivo com grupo de comparação. Nosso grupo de estudo foi constituído por 99 pacientes, avaliadas no período de janeiro de 1995 a janeiro de 2004. Foram analisados e comparados dois grupos: 74 gestantes sensibilizadas pelo fator Rh cuja anemia fetal foi acompanhada pela espectrofotometria (grupo SE) e 25 gestantes sensibilizadas pelo fator Rh cuja anemia fetal foi acompanhada pela dopplervelocimetria (grupo SD). Avaliamos a presença ou não de alterações ultra-sonográficas no acompanhamento pré-natal e confrontamos os dois grupos de estudo. RESULTADOS: No grupo cuja anemia fetal foi acompanhada através da espectrofotometria (grupo SE), apuramos modificações placentárias, principalmente o aumento da espessura e sua alteração textural, mais assiduamente que as encontradiças no grupo de gestantes sensibilizadas, em que a anemia foi determinada através da dopplervelocimetria (grupo SD) $(64 \% \times 32 \%, p=6,294)$. CONCLUSÃO: As alterações ultra-sonográficas foram detectadas em dobro quando a anemia foi avaliada pela espectrofotometria em comparação com o grupo seguido pela dopplervelocimetria.

Unitermos: Isoimunização; Anemia fetal; Artéria cerebral média; Ultra-som Doppler; Aloanticorpos; Eritroblastose fetal.

Abstract Ultrasound findings in Rh-alloimmunized pregnancies assessed by spectrophotometric analysis of amniotic fluid and Doppler velocimetry of fetal middle cerebral artery.

OBJECTIVE: To evaluate and compare existing ultrasound findings in women with Rh-alloimmunized pregnancies with diagnosis of fetal anemia by spectrophotometric analysis of amniotic fluid or Doppler ultrasound of the fetal middle cerebral artery. MATERIALS AND METHODS: This was an observational descriptive study involving 99 patients evaluated between January 1995 and January 2004. Patients were divided into two groups: $74 \mathrm{Rh}$-isoimmunized women submitted to spectrophotometry of the amniotic fluid (group S) and $25 \mathrm{Rh}$-isoimmunized women submitted to Doppler ultrasound of fetal middle cerebral artery (group D) to evaluate fetal anemia. Ultrasound findings in the two groups were compared. RESULTS: Placental anomalies, mainly placentomegaly and textural irregularities were more frequently seen in pregnant women followed up with spectrophotometry of the amniotic fluid compared to those followed up with Doppler ultrasound $(64 \% \times 32 \%, p=6,294)$. CONCLUSION: The frequency of abnormal ultrasound findings was 2 -fold higher in pregnancies evaluated with spectrophotometry of the amniotic fluid compared to those followed up with Doppler ultrasound.

Keywords: Red blood cell isoimmunization; Fetal anemia; Middle cerebral artery; Doppler ultrasonography; Isoantibodies; Fetal erythroblastosis.

\footnotetext{
* Trabalho realizado na Disciplina de Medicina Fetal do Departamento de Obstetrícia da Universidade Federal de São Paulo/ Escola Paulista de Medicina (Unifesp/EPM), São Paulo, SP.

1. Professor Adjunto do Departamento de Obstetrícia da Unifesp/EPM.

2. Professores Titulares do Departamento de Obstetrícia da Unifesp/EPM.

3. Professor Assistente do Departamento de Obstetrícia da Unifesp/EPM.

4. Pós-graduandos do Departamento de Obstetrícia da Unifesp/EPM.

Endereço para correspondência: Prof. Dr. Luciano Marcondes Machado Nardozza. Avenida Lopes de Azevedo, 888. São Paulo, SP, 05603-001. E-mail: lunardozza@uol.com.br

Recebido para publicação em 25/4/2005. Aceito, após revisão, em 25/5/2005.
}

\section{INTRODUÇÃO}

A aloimunização pelas células vermelhas do sangue é caracterizada por ser distúrbio imunológico conseqüente a incompatibilidade sanguínea materno-fetal, que determina doença hemolítica no feto e recém-nascido. Há destruição excessivamente rápida das hemácias, que produz intensa anemia, hiperbilirrubinemia e grave edema generalizado, e é causada por anti- corpos específicos, produzidos pela mãe, que passam para a circulação fetal durante a gravidez.

Aclarada a etiopatogenia, os pesquisadores do assunto buscaram medidas terapêuticas que melhorassem o alto índice de mortalidade perinatal desses conceptos, e métodos que pudessem detectar os diferentes graus de comprometimento fetal. Liley ${ }^{(\mathbf{1})}$, em 1961, descreveu método de leitura espectrofotométrica para determinar 
indiretamente a concentração de bilirrubina no líquido amniótico e avaliar o estado hemolítico, e o possível estado hematimétrico do concepto. A espectrofotometria precedida da amniocentese converteuse em técnica de aceitação geral e passou a ser considerada básica no manuseio da gestante sensibilizada ao fator Rh. Em meados da década de 80 , os estudos com o efeito Doppler acoplado à ultra-sonografia tornaram a avaliação da hemodinâmica fetal mais apurada. Pesquisas com a dopplervelocimetria serviram para elucidar importantes aspectos dos ajustes hemodinâmicos do concepto frente à anemia. $\mathrm{O}$ método mais fiel para determinar a gravidade da anemia fetal é sem dúvida a avaliação hematimétrica do concepto. No entanto, a cordocentese para a coleta da amostra do sangue fetal é procedimento de risco, associado a piora da aloimunização maternal e a perda fetal ${ }^{(2)}$. No meio da década de 90 , diversos trabalhos ${ }^{(3-7)}$ estabeleceram que o feto responde à anemia por meio de modificações hemodinâmicas arteriais e venosas. Recentemente, Mari et al. ${ }^{(\mathbf{8})}$ sugeriram que a velocidade do pico sistólico da artéria cerebral média fetal (MCA-PSV) pode ser usada como método não invasivo para quantificar a anemia fetal e decidir quando usar a transfusão intra-uterina ou antecipação do parto. No entanto, mesmo com as considerações desses autores e de ou$\operatorname{tros}^{(9-12)}$, e a despeito das teóricas vantagens do método, a dopplervelocimetria não é prática rotineira devido à pouca experiência deste teste no nosso meio.

Este trabalho tem como objetivo avaliar e confrontar a presença de alterações ultra-sonográficas nas gestações Rh negativo sensibilizadas, quando a anemia fetal foi determinada ou pela espectrofotometria do líquido amniótico, ou pela dopplervelocimetria da artéria cerebral média.

\section{MATERIAIS E MÉTODOS}

Nosso grupo de estudo foi constituído por 99 pacientes, avaliadas no Setor de Atendimento à Gestante $\mathrm{Rh}$ negativo e Aloimunizada da Universidade Federal de São Paulo/Escola Paulista de Medicina, no período de janeiro de 1995 a janeiro de 2004. Apenas as gestantes sensibilizadas pelos anticorpos anti-eritrocitários anti-D foram analisadas. Dividimos o grupo de estudo em gestantes Rh negativo sensibilizadas acompanhadas, quanto à anemia fetal, pela espectrofotometria (grupo SE), formado por 74 pacientes, e em gestantes Rh negativo sensibilizadas acompanhadas pela dopplervelocimetria (grupo SD) da artéria cerebral média (acompanhadas a partir de 2001, totalizando 25 gestantes).

Foi avaliada, nos dois grupos, a presença ou não de alterações ultra-sonográficas (sinais que possam sugerir o início da descompensação fetal a caminho da hidropisia, como a alteração volumétrica do líquido amniótico, áreas de maior ecogenicidade placentária, aumento da espessura placentária, e ascite incipiente). Constituímos dois subgrupos: os que apresentaram qualquer sinal ultra-sonográfico (com US) e aqueles que não mostraram descompensação fetal inicial pelo ultra-som (sem US).

Foi utilizado aparelho Power Vision 6000 (Toshiba, Tóquio, Japão) com transdutor convexo de 3,5 MHz. O estudo dopplervelocimétrico foi feito seguindo as recomendações de Mari et al. ${ }^{(\mathbf{8})}$. O "color" Doppler é usado na identificação da artéria cerebral média na base do cérebro, utilizando corte transversal, com a visualização do osso esfenóide, por onde corre esta artéria. Doppler pulsátil é captado no terço proximal do vaso, com o cuidado de corrigir o ângulo de insonação para menos de $20^{\circ}$. Três medidas da velocidade do pico sistólico são obtidas e a maior é registrada. Aquelas que apresentarem valores acima de 1,5 múltiplo da mediana, para a idade gestacional correspondente, são as que têm anemia moderada ou grave, com sensibilidade de $100 \%$, segundo esses autores.

O estudo do líquido amniótico pela espectrofotometria visa à quantificação dos pigmentos biliares cujos níveis são proporcionais à hemólise fetal. A espectrofotometria fornece, no comprimento de onda de $450 \mathrm{~m} \mu$, a diferença de densidade óptica $\left(\Delta \mathrm{DO}_{450}\right)$ entre a concentração de bilirrubina indireta fetal e o padrão. O líquido amniótico foi obtido mediante punção abdominal orientada por ultra-sonografia, sob anestesia local, com agulha apropriada (B-D Spinal Needle 20 Gauge-3,5). Aspira-se cerca de $10 \mathrm{ml}$ de líquido, com o cuidado de não aspirar sangue concomitantemente. O material é protegido da luz e en- caminhado para análise espectrofotométrica. O resultado obtido é levado a um gráfico de escalas semilogarítmicas, que estabelece relação entre a diferença de densidade óptica $\left(\Delta \mathrm{DO}_{450}\right)$ obtida e a idade gestacional, permitindo elaborar conduta específica para cada caso ${ }^{(\mathbf{1})}$. Foi indicado esse exame quando os títulos de anticorpos maternos (teste indireto de Coombs) foram iguais ou superiores a 1:16.

No estudo de possíveis associações nas tabelas analisadas, foi usado o teste do quiquadrado $\left(\chi^{2}\right)$, obedecendo-se às restrições de Cochran, e quando estas estiveram presentes, foi realizado o teste exato de Fisher. Em função do tamanho da amostra, foi levado em consideração, no cálculo do $\chi^{2}$, a correção de Yates. O nível de rejeição para a hipótese de nulidade foi fixado sempre em um valor $\leq 0,05$ (5\%). Quando a estatística calculada mostrou significância, foi assinalada por asterisco (*); caso contrário, isto é, não significante, usou-se NS.

\section{RESULTADOS}

Nosso estudo mostrou que as alterações ultra-sonográficas foram mais freqüentes no grupo de pacientes cuja anemia fetal foi acompanhada pela espectrofotometria do líquido amniótico (64\%), quando comparado com o grupo de gestantes que tiveram o acompanhamento da anemia fetal pela dopplervelocimetria da artéria cerebral média (32\%) (Tabela e Gráfico 1).

Tabela e Gráfico 1 Análise ultra-sonográfica em 99 grávidas $\mathrm{Rh}^{-}$sensibilizadas.

\begin{tabular}{|l|c|c|r|c|}
\hline \multirow{2}{*}{} & \multicolumn{2}{|c|}{ Grupo SE } & \multicolumn{2}{c|}{ Grupo SD } \\
\cline { 2 - 5 } & $\mathrm{N}$ & $\%$ & $\mathrm{~N}$ & $\%$ \\
\hline Com alteração & 47 & $64 \%$ & 8 & $32 \%$ \\
Sem alteração & 27 & $36 \%$ & 17 & $68 \%$ \\
\hline
\end{tabular}

$\chi^{2}$ calculado $=6,294^{*}$.

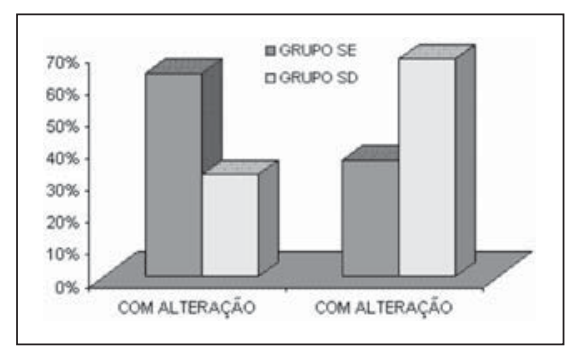

Grupo SE: grávidas $\mathrm{Rh}^{-}$sensibilizadas acompanhadas pela espectrofotometria. Grupo SD: grávidas $\mathrm{Rh}^{-}$sensibilizadas acompanhadas pela dopplenvelocimetria. 


\section{DISCUSSÃO}

A aloimunização pelo fator Rh é a doença obstétrica mais eloqüente para representar o século passado. Foi caracterizada clinicamente, conhecida a sua etiopatogenia, estabelecido o tratamento e realizada a profilaxia adequada para todos os séculos que virão. No nosso meio, no entanto, sua incidência vem caindo muito lentamente, pois a introdução da profilaxia ainda não é universal devido ao elevado custo e à desinformação médica. A sensibilização pelo fator Rh determina ominoso porvir para o concepto, em que pese todo avanço propedêutico que dispomos.

Em nossa vivência, as alterações ultrasonográficas no acompanhamento pré-natal das gestantes sensibilizadas são tardias, como já observaram Oepkes ${ }^{(\mathbf{9})}$ e Divakaran et al. ${ }^{\mathbf{( 1 3 )}}$. No grupo cuja anemia fetal foi acompanhada por meio da espectrofotometria (grupo SE), encontramos modificações placentárias, principalmente o aumento da espessura e da alteração textural, que são mais assíduas que as encontradiças no grupo de gestantes sensibilizadas, em que a anemia foi determinada pela dopplervelocimetria (grupo SD), como mostra a Tabela e o Gráfico 1. Julgamos que a espectrofotometria do líquido amniótico diagnostica a hemólise e não a anemia fetal, e destarte exibe mais tardiamente as alterações ecográficas de comprometimento fetal. A dopplervelocimetria, portanto, detecta a anemia fetal antes que as alterações ultra-sonográficas sejam evidenciadas, resguardando assim o concepto e o recém-nascido.

Cumpre ressaltar as vantagens que a dopplevelocimetria possui para o manuseio pré-natal das gestantes sensibilizadas.
A amniocentese, para a realização da espectrofotometria, é método invasivo que pode acarretar riscos maternos e para o concepto. As complicações incluem trabalho de parto prematuro, corioamnioite, ruptura pré-termo das membranas, trauma fetal, punção acidental do cordão umbilical, bradicardia, e morte fetal. Acrescenta-se o fato que a espectrofotometria é método indireto para avaliar a anemia fetal, estando associada a falso-positivos e falso-negativos (ao redor de 10\% cada). Lembramos ainda que na aloimunização pelo fator Rh o acompanhamento da anemia fetal é constante, sendo necessária, freqüentemente, a repetição de nova amostra do líquido amniótico, aumentando sobremaneira os riscos acima expostos.

Em conclusão, a mensuração da velocidade do pico sistólico da artéria cerebral média pela dopplervelocimetria é método eficaz, seguro, não invasivo e de fácil repetição, fornecendo de imediato o resultado e, portanto, devendo fazer parte da rotina propedêutica do acompanhamento da anemia fetal nas gestantes aloimunizadas. Por meio deste método para avaliação da anemia fetal, as alterações ultra-sonográficas pouco foram evidenciadas, mostrando que o concepto foi mais resguardado.

\section{CONCLUSÃO}

Na sistemática empregada na avaliação da anemia fetal pelo protocolo de assistência pré-natal do setor de aloimunização pelo fator Rh, julgamos lícito concluir que as alterações ultra-sonográficas foram detectadas em dobro quando a anemia foi avaliada pela espectrofotometria em comparação com o grupo seguido pela dopplervelocimetria.

\section{REFERÊNCIAS}

1. Liley AW. Liquor amnii analysis in the management of the pregnancy complicated by rhesus sensitization. Am J Obstet Gynecol 1961;82:1359-1370.

2. Nicolaides KH, Soothill PW, Clewell WH, Rodeck $\mathrm{CH}$, Mibashan RS, Campbell S. Fetal haemoglobin measurement in the assessment of red cell isoimmunisation. Lancet 1988;14:1073-1075.

3. Rightmire DA, Nicolaides KH, Rodeck CH, Campbell $\mathrm{S}$. Fetal blood velocities in $\mathrm{Rh}$ isoimmunization: relationship to gestational age and to fetal hematocrit. Obstet Gynecol 1986;68:233-236.

4. Copel JA, Grannum PA, Green JJ, Belanger K, Hobbins JC. Pulsed Doppler flow-velocity waveforms in the prediction of fetal hematocrit of the severely isoimmunized pregnancy. Am J Obstet Gynecol 1989;161:341-344.

5. Hecher K, Snijders R, Campbell S, Nicolaides K. Fetal venous, arterial, and intracardiac blood flows in red blood cell isoimmunization. Obstet Gynecol 1995;85:122-128.

6. Nicolaides KH, Bilardo CM, Campbell S. Prediction of fetal anemia by measurement of the mean blood velocity in the fetal aorta. Am J Obstet Gynecol 1990;162:209-212.

7. Vyas S, Nicolaides KH, Campbell S. Doppler examination of the middle cerebral artery in anemic fetuses. Am J Obstet Gynecol 1990;162:10661068.

8. Mari G, Deter RL, Carpenter RL, et al. Noninvasive diagnosis by Doppler ultrasonography of fetal anemia due to maternal red-cell alloimmunization. Collaborative Group for Doppler Assessment of the Blood Velocity in Anemic Fetuses. N Engl J Med 2000;342:9-14.

9. Oepkes D. Invasive versus non-invasive testing in red-cell alloimmunized pregnancies. Eur J Obstet Gynecol Reprod Biol 2000;92:83-89.

10. Pereira L, Jenkins TM, Berghella V. Conventional management of maternal red cell alloimmunization compared with management by Doppler assessment of middle cerebral artery peak systolic velocity. Am J Obstet Gynecol 2003;189:1002-1006.

11. Stefos T, Cosmi E, Detti L, Mari G. Correction of fetal anemia on the middle cerebral artery peak systolic velocity. Obstet Gynecol 2002;99:211-215.

12. Whitecar PW, Moise KJ Jr. Sonographic methods to detect fetal anemia in red blood cell alloimmunization. Obstet Gynecol Surv 2000;55:240-250.

13. Divakaran TG, Waugh J, Clark TJ, Khan KS, Whittle MJ, Kilby MD. Noninvasive techniques to detect fetal anemia due to red blood cell alloimmunization: a systematic review. Obstet Gynecol 2001;98:509-517. 